\title{
Prevalence of intestinal parasitic infections of carrier pigeons from central Poland in the years 2012-2019
}

\author{
JUSTYNA BARTOSIK, JACEK ŁOJEK*, WIKTORIA VETTER, \\ PAWEŁ GÓRSKI, MONIKA ŁUKASIEWICZ*, WOJCIECH ZYGNER
}

Department of Preclinical Sciences, Institute of Veterinary Medicine, *Department of Animal Breeding and Production,
Institute of Animal Sciences, Warsaw University of Life Sciences - SGGW, Ciszewskiego 8, 02-786 Warsaw, Poland

Bartosik J., Łojek J., Vetter W., Górski P., Łukasiewicz M., Zygner W.

Prevalence of intestinal parasitic infections of carrier pigeons from central Poland in the years 2012-2019

\section{Summary}

The aim of the study was to establish the prevalence of intestinal parasitic infections of carrier pigeons from central Poland depending on the year and season. The coproscopic method (flotation with saturated $\mathrm{NaCl}$ ) was used to examine 324 fecal samples from carrier pigeons. The average prevalence of parasitic infections reached

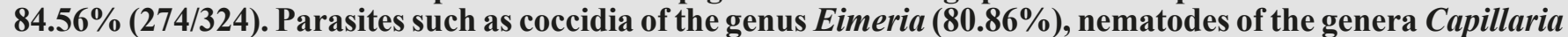
(32.71\%) and Ascaridia (13.58\%) were detected. Infection with tapeworms (Raillietina) was observed $(0.3 \%)$ only in one fecal sample. Coccidiosis was the most prevalent infection during the whole period of the study (2012-2019), ranging from $\mathbf{7 0 . 0 3 \%}$ in the $2014-2015$ period up to $90.5 \%(P \leq 0.02)$ in $2012-2013$. Infections with Capillaria $(\mathrm{P} \leq \mathbf{0 . 0 5})$ and Eimeria were diagnosed more frequently in the autumn-winter seasons then in spring-summer.

Keywords: pigeon, intestinal parasites, season, year

Pigeon breeding is very popular in Poland. Currently, about 41,800 members are united in the Polish Association of Racing Pigeon Breeders and their number is still growing (9). Control of parasitic infections in pigeons is a great challenge for veterinary surgeons. Keeping birds in a large numbers is one of the important factors in the spread of parasitic infections among these animals. Numerous studies on the prevalence of pigeon parasites have been reported in Poland $(3,15,22)$. However, only a few studies have included the association between the season of the year and the prevalence of helminth infections $(2,17,23)$. Analysis of the influence of the season of the year on the prevalence of parasitic infections might provide further insight into the ecology of pigeon parasites species and may facilitate the implementation of the certain control measures (17).

The aim of the study was to establish the prevalence of parasitic infections of carrier pigeons from central Poland depending on the year and season.

\section{Material and methods}

The coproscopic studies were conducted from January 2012 to December 2019 in Warsaw. A total of 324 pooled fecal samples were collected from different parts of each loft from 7 districts in the territory of the Masovian voivodeship (Fig. 1). The samples were declared as derived

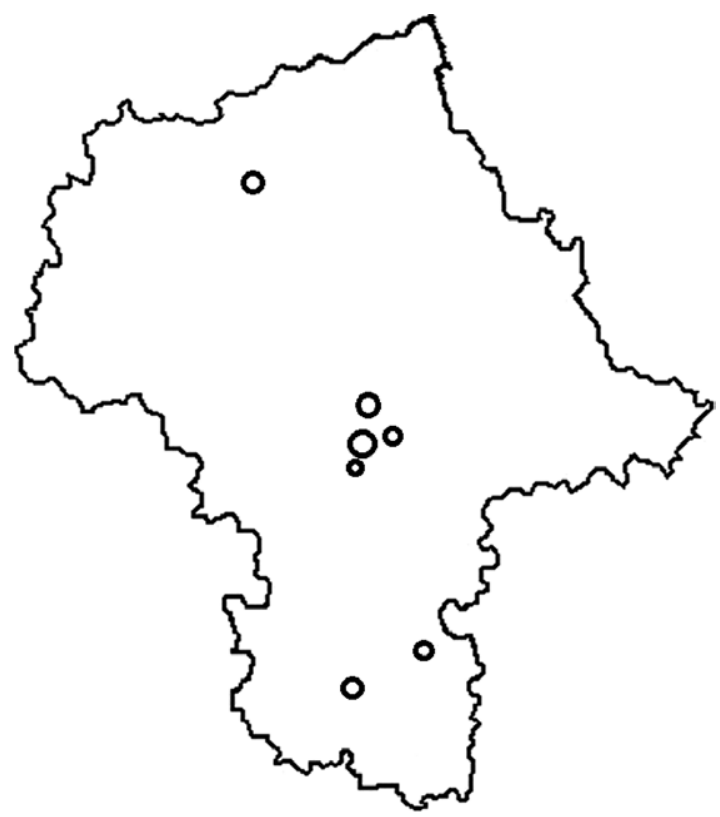

Fig. 1. The origin of samples marked on map of the Masovian voivodeship 
from racing pigeons. Before examination, each collective sample was mixed and $5 \mathrm{~g}$ sample of feces was analyzed using the flotation method (saline solution, specific gravity 1.2). Fecal samples were examined during each of the four biennial periods (2012-2013, 2014-2015, 2016-2017, 2018-2019), and six two-month periods (January-February, March-April, May-June, July-August, September-October, November-December) for prevalence of gastrointestinal parasites. Before coproscopy fecal samples were stored at a temperature of $+4^{\circ} \mathrm{C}$, and were examined within 3 days. The influence of the four biennial periods and six twomonth periods on the prevalence of intestinal parasites was determined using the Pearson's chi-square test and Fischer's exact test with the SPSS 21.0 Statistical Package computer program. Two levels of significance were assigned: $\mathrm{P} \leq 0.01$ as highly significant and $\mathrm{P} \leq 0.05$ as significant.

\section{Results and discussion}

In total, parasites were detected in 274 (84.56\%) out of 324 fecal samples. Parasites such as coccidia of the genus Eimeria $(80.86 \%)$, nematodes of the genera Capillaria (32.71\%) and Ascaridia (13.58\%) were detected. Infection with tapeworms (Raillietina spp.) was observed only in one fecal sample $(0.3 \%)$. Figure 2 presents the prevalence of the infections during the whole period. Coccidiosis was the most prevalent infection. It oscillated between $70.03 \%$ and $90.5 \%$. The highest prevalence of parasitic infections was noted in first examined period 2012-2013 (Eimeria - 90.5\%, Capillaria - 39\%). The prevalence of roundworm infection has successively increased twice during the investigated years from $9.5 \%(2012-2013)$ to $15.4 \%$ (2014-2015) and from $12.6 \%$ (2016-2017) to $22 \%$ (2018-2019). Mixed infections were found in 36.11\% $(\mathrm{N}=117)$ of the birds. Coinfections caused by two genera (Eimeria and Capillaria) were observed in $65.81 \%$ samples and mixed infections caused by three genera of parasites (Eimeria, Capillaria, Ascaridia) were detected in $18.8 \%$ of fecal samples. Table 1. presents seasonal prevalence of infections in the whole examined period 2012-2019. The highest prevalence of all infections was observed in November and December. Capillaria eggs $(\mathrm{P} \leq 0.05)$ and Eimeria oocysts were detected in fecal samples more frequently in the season of autumn-winter then in the spring-summer season. The influence of the season on roundworm infection was not unequivocal.

The study showed high prevalence of intestinal parasitioses in pigeons from the Mazowieckie Voivodeship caused by parasites of the genera Eimeria, Capillaria and Ascaridia. This study also showed extremely low prevalence of tapeworm infection. However, it should be emphasized that the results of the fecal flotation method in pigeons infected with tapeworms may be false negative, and the most sensitive method for the diagnosis of the infections with the cestodes of the family Davaineidae is microscopic examination of the mucosal scraping from the small intestine (21). Thus,

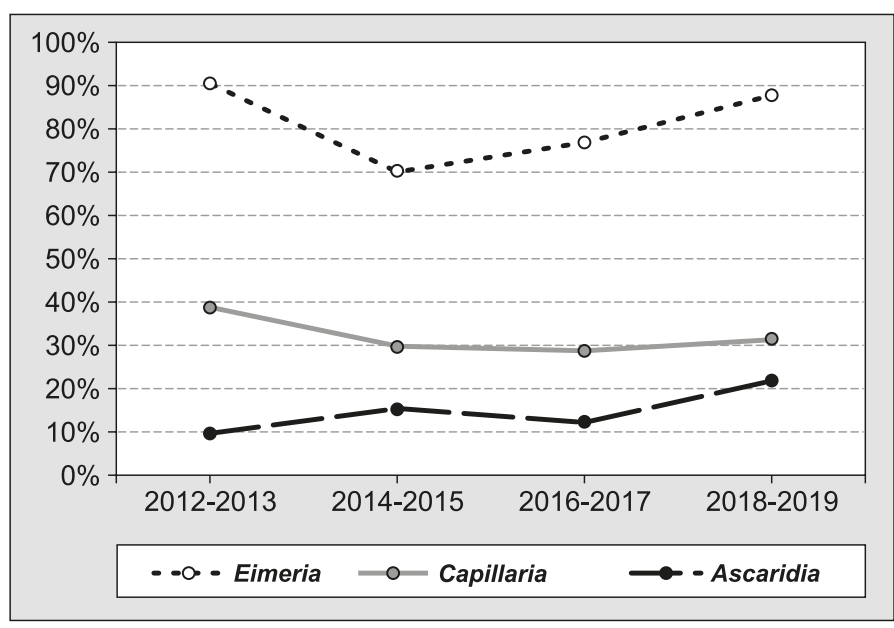

Fig. 2. Prevalence of parasitic infection of carrier pigeons from central Poland depending on the year

Tab. 1. Prevalence of parasitic infection of carrier pigeons from central Poland depending on season (months)

\begin{tabular}{|c|c|c|c|c|c|c|}
\hline Months & $\begin{array}{c}\text { Prevalence } \\
\% / \mathrm{n} \\
\text { Eimeria }\end{array}$ & $\mathbf{P}$ & $\begin{array}{c}\text { Prevalence } \\
\% / \mathrm{n} \\
\text { Capillaria }\end{array}$ & $\mathbf{P}$ & $\begin{array}{c}\text { Prevalence } \\
\% / \mathrm{n} \\
\text { Ascaridia }\end{array}$ & $\mathbf{P}$ \\
\hline Jan-Feb & $74.0 \% / 77$ & \multirow{6}{*}{0.37} & $31.7 \% / 33$ & \multirow{6}{*}{0.05} & $15.4 \% / 16$ & \multirow{6}{*}{0.19} \\
\hline Mar-Apr & $82.2 \% / 37$ & & $22.2 \% / 10$ & & $6.7 \% / 3$ & \\
\hline May-Jun & $80.6 \% / 29$ & & $27.8 \% / 10$ & & $8.3 \% / 3$ & \\
\hline Jul-Aug & $83.7 \% / 36$ & & $23.3 \% / 10$ & & $11.6 \% / 5$ & \\
\hline Sept-0ct & $87.5 \% / 28$ & & $43.8 \% / 14$ & & $9.4 \% / 3$ & \\
\hline Nov-Dec & $85.9 \% / 55$ & & $45.3 \% / 29$ & & $21.9 \% / 14$ & \\
\hline
\end{tabular}

Explanation: $\mathrm{P} \leq 0.01$ as highly significant; $\mathrm{P} \leq 0.05$ as significant

tapeworm infections were not included into statistical analyses because of extremely rare detection in coproscopic examinations.

There are 3 Eimeria species in domestic pigeons such as Eimeria labbeana, E. columbarum, or E. columbae. All these three species were detected in these birds in Poland $(3,15)$. Similar studies on the prevalence of intestinal parasites in pigeons were conducted in south-eastern Poland (22). That research also showed the high prevalence of intestinal parasitic infection, and the most prevalent was coccidiosis (22). Similar results were observed in other studies. Various reports from Poland indicated the prevalence of infection with these protozoa was between $4.7 \%$ and even $100 \%$ (3, 6, 12). Balicka-Ramisz and Pilarczyk (2014) showed that the most prevalent infection in pigeons in Poland was caused by E. labbeana.

In this study the prevalence of nematode infections (Capillaria and Ascaridia) was significantly lower than Eimeria infections. In the Lower Silesian Voivodship, the prevalence of infection with these nematodes was found at a much higher level: Capillaria - 48.1\%, Ascaridia - 30.4\% (13). Similarly the study from south-eastern Poland showed a lower prevalence of nematode infections: Capillaria (35.8\%), Ascaridia $(12.5 \%)(22)$. On the contrary in Pomerania (northern 
Poland), eggs of these nematodes were found much less frequently in pigeon feces: Capillaria $-8.2 \%$, and Ascaridia - 7\% of fecal samples (6). The only species of the genus Ascaridia in pigeons is A. columbae (4). This species was detected in Poland in many studies $(5,22)$. Among various species of the genus Capillaria infecting pigeons only $C$. columbae, currently known as Baruscapillaria obsignata, was detected in these animals in Poland $(14,19,22)$.

Coproscopic examination of pigeon feces conducted in Slovenia also showed a high prevalence of coccidia $(71.9 \%)$ and rather low of nematode infection, which ranged from $4.3 \%$ (Ascaridia) to $26.6 \%$ (Capillaria) (8). Similar results were obtained in India (Eimeria $75 \%$, nematodes $-5 \%$ ) and in Turkey (Eimeria - 45\%, Capillaria - 12.1\%, and Ascaridia - 5.1\%) $(10,16)$. Moreover, Sari et al. (2008) detected eggs of nematodes Heterakis gallinarum (3.7\%) and Syngamus sp. (1.7\%) in pigeon feces (16). In the studies from Libya and on pigeon parasites fecal examination revealed eggs of nematodes (Capillaria - 4\%, Ascaridia - 22\%) and also adult tapeworms such as: Raillietina tetragona (2\%), Raillietina echinobothrida (32\%), Raillietina cesticillus (4\%) (1). Infections of intestinal parasites were much more common in birds from Pakistan, Capillaria eggs were found in $67.2 \%$ pigeon feces, and roundworm eggs in $32.8 \%$ of fecal samples (20).

The influence of the season of the year on the prevalence of the intestinal parasitic infections is not unambiguous. Researchers from Nigeria showed higher prevalence of coccidiosis during wet seasons $(8.96 \%$ - Jun-Aug) in comparison to dry seasons (5.98\% - Feb-Apr) $(\mathrm{P}<0.05)(2)$. However, in other studies opposite trends have been observed. In Turkey the highest prevalence of $A$. columbae was observed in the autumn months (17). This study showed a very high prevalence of Eimeria infection during all seasons (80.6-87.5\%), and the prevalence of coccidiosis subtly decreased to $74 \%$ in winter months (Jan-Feb). This process could be explained by the biology of the parasite. Oocysts are released into the environment in their unsporulated form. In optimal conditions of temperature and humidity sporulation process takes at least $24 \mathrm{~h}$. The sporulated oocysts are an infective form of the parasite and may cause the infection in other hosts. However, low temperature may inhibit the sporulation process. Thus, decreased number of infective oocysts in the environment in cold months may have an influence on decreased prevalence of infection in the herd in winter (7).

The prevalence of nematode infections was more dynamic during all seasons (Tab. 1). It is suspected that anthelmintic treatments may play a role in this phenomenon. In Poland, one of the periodic dewormings is recommended in pigeons in early spring and autumn, which allows birds to prepare better for breeding and flights season $(6,18)$. That could explain the rapid decline in the prevalence of nematode infections (Ascaridia and Capillaria) in the spring months. It should be emphasized there are only few therapeutics officially registered for the control of pigeon endoparasites in Poland (11). Levamisole is the only drug which can be used against infections of the trachea and intestinal nematodes of birds (Syngamus, Ascaridia, Heterakis, Capillaria, Amidostomum). However, it is not an effective drug against Eimeria infection. There is currently no officially registered drug for the treatment of eimeriosis in pigeons in Poland, despite the well known effectiveness of toltrazuril $(11,12)$. The rapid decrease of prevalence of roundworm infection in pigeons in the autumn months (Sept-Oct) could be also connected with autumn deworming (18). However, in case of capilariosis in the same period was observed opposite trends, prevalence of infections increase from $23.3 \%$ (Jul-Aug) to $43.8 \%$ (Sept-Oct). The reasons for the significantly increasing prevalence of Capillaria infections could be connected with the resistance of these nematodes to the anthelmintics commonly used in control and their schematic use without the prior diagnosis. Capillariosis in many flocks of pigeons is becoming a dominant problem. Elimination of the mentioned parasite due to the long survival of infective forms in the environment is very difficult $(11,22)$.

The McMaster method was not used in this study. Thus the authors cannot exclude that in some cases of infected animals the number of parasites was low. Nevertheless these animals may infect other pigeons, and the presence of asymptomatic carriers in the flock may be one of the factors influencing on the persistence of parasitic infections.

Based on many studies, it can be concluded that pigeons are a reservoir of many endoparasites. In Poland and selected parts of Europe, the most commonly found parasites are coccidia of the genus Eimeria. However, the prevalence of the genera Capillaria and Ascaridia varied in European countries.

\section{References}

1. Alkharigy F. A., El Naas A. S., El Maghrbi A. A.: Survey of parasites in domestic pigeons (Columbia livia) in Tripoli, Libya. Open. Vet. J. 2018, 8, 4, 360-366.

2. Balarabe R. M., Malang K. S., Rowland I. S. A., Auwalu H. A.: Coccidiosis of domestic pigeons (Columba livia domestica Gmelin, 1789) in Kano State, Nigeria. Ann. Parasitol. 2017, 63, 199-203.

3. Balicka-Ramisz A., Pilarczyk B.: Occurrence of coccidia infection in pigeons in amateur husbandry. Diagnosis and prevention. Ann. Parasitol. 2014, 60, 93-97.

4. Bessat M., Dewair A.: Assessment of the inhibitory effects of disinfectants on the embryonation of Ascaridia columbae eggs. PLoS One 2019, 14(5): e0217551.

5. Bobrek K., Gawet A., Piasecki T., Bobusia K., Mazurkiewicz M.: Extensiveness and intensity of invasion of intestinal parasites in flocks of racing pigeons in the south of Poland. Acta. Sci. Pol. 2012, 11, 5-10.

6. Chorąży R.: Pasożyty wewnętrzne u gołębi. Poradnik hodowcy 2013, 8, 1-7.

7. Doner S., Szeleszczuk P., Żbikowski A.: Chicken coccidiosis. Życie Wet. 2019, 94, 494-502.

8. Dovc A, Vergles O., Rataj A., Bole-Hribovsek V., Krapez U., Dobeic M.: Health status of free-living pigeons (Columba livia domestica) in the city of Ljubljana. Acta. Vet. Hung. 2004, 52, 2, 219-226.

9. Federation Colombophile Internationale https://pigeonsfci.org/memberfederation/ 25.03.2020. 
10. Jayentakumar Singh L., Mohilal N.: Gastrointestinal parasitic infection in diverse species of domestic birds of Manipur, India. J. Parasit. Dis. 2017, 41, 1, 142-146.

11. Ledwon' A., Szeleszczuk P.: Comments on the treatment of the most common endoparasitoses of the domestic pigeons. Życie Wet. 2016, 91, 177-183.

12. Michalczyk M., Raś-Noryńska M., Sokót R.: Efficacy of toltrazuril (Baycox) for Eimeria spp. control in racing pigeons. Med. Weter. 2011, 67, 406-408.

13. Piasecki T.: Evaluation of urban pigeon (Columba livia f. urbana) health status in relation to their threat to human's health. Med. Weter. 2006, 62, 531-535.

14. Pojmańska T., Niewiadomska K., Okulewicz A.: Pasożytnicze helminty Polsk - gatunki, żywiciele, białe plamy. Polskie Towarzystwo Parazytologiczne, Warszawa 2007.

15.Raś-Noryńska M., Michalczyk M., Sokół R.: Coccidia infections in homing pigeons of various age during the racing season. Wiad. Parazytol. 2011, 57, $165-168$.

16. Sari B., Karatepe B., Karatepe M., Kara M.: Parasites of domestic (Columba livia domestica) and wild (Columba livia livia) pigeons in Nigde, Turkey. Vet. Inst. Pulawy 2008, 52, 551-554.

17. Senlik B., Gulegen E., Akyol V.: Effect of age, sex and season on the prevalence and intensity of helminth infections in domestic pigeons (Columba livia) from Bursa Province, Turkey. Acta. Vet. Hung. 2005, 53, 4, 449-456.
18. Szeleszczuk P.: Praktyczne uwagi na temat terapii i profilaktyki chorób gołębi domowych. Mag. Weter. 1995, 4, 25-30.

19. Tamaru M., Yamaki S., Jimenez L. A., Sato H.: Morphological and molecular genetic characterization of three Capillaria spp. (Capillaria anatis, Capillaria pudendotecta, and Capillaria madseni) and Baruscapillaria obsignata (Nematoda: Trichuridae: Capillariinae) in avians. Parasitol. Res. 2015, 114, 4011-4022.

20. Tanveer M. K., Kamran A., Abbas M., Umer N. C., Azhar M. A., Munir M.: Prevalence and chemo-therapeutical investigations of gastrointestinal nematodes in domestic pigeons in Lahore, Pakistan. Trop. Biomed. 2011, 28, 102-110.

21. Taylor M. A., Coop R. L., Wall R. L.: Veterinary Parasitology. $3^{\text {rd }}$ ed. Blackwell Publishing, Ames, Iowa 2007, p. 470-471.

22.Tomczuk K., Studzinska M., Szczepaniak K., Grzybek M., DemkowskaKutrzepa M., Roczen-Karczmarz M., Abdulhammza Abbass Z., Jankuszew A., Bojar $W$.: Endoparasites in carrier and fancy pigeons in south-western Poland. Med. Weter. 2017, 73, 731-735.

23. Wysocka-Lipińska N., Choraży R., Tkachenko H., Kurhaluk N.: Occurrence of parasitic diseases of pigeons Columba livia f. domestica in Pomeranian in the years 2008-2012. Słupskie Prace Biol. 2014, 11, 235-249.

Corresponding author: Justyna Bartosik, PhD, assistant professor, Ciszewskiego 8, 02-786 Warszawa; e-mail: justyna_bartosik@sggw.edu.pl 